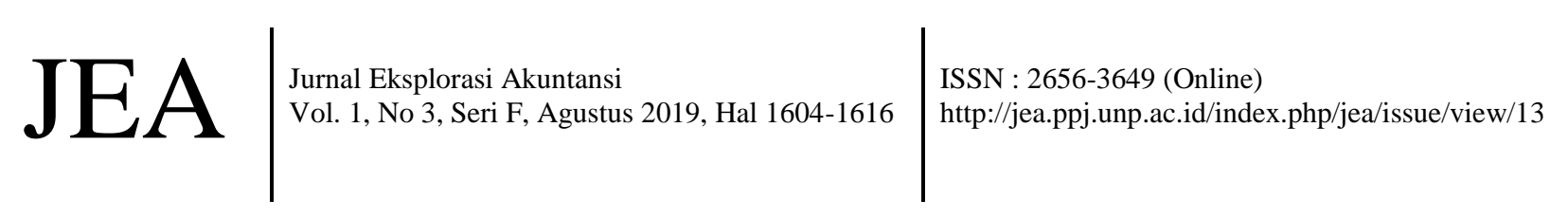

\title{
ANALISIS PENGUNGKAPAN STANDAR AKUNTANSI SYARIAH AAOIFI PADA BANK SYARIAH DI INDONESIA DAN MALAYSIA PERIODE TAHUN 2017-2018
}

\author{
Fajar Yufrikal Azlan ${ }^{1}$, Vanica Serly ${ }^{2}$ \\ 1)Alumni Jurusan Akuntansi Fakultas Ekonomi, Universitas Negeri Padang \\ ${ }^{2)}$ Jurusan Akuntansi Fakultas Ekonomi, Universitas Negeri Padang \\ Korespondensi: fajarazlan15@gmail.com
}

\begin{abstract}
This study aims to examine the compliance of AAOIFI sharia accounting standards disclosures in Islamic Banks in Indonesia and Malaysia in 2017 and 2018. This study measures compliance by looking at three Islamic banks' products in Islamic, mudaraba, and musharaka. Data was collected from the annual report of 12 Islamic commercial banks in Indonesia and 15 Islamic commercial banks in Malaysia for 2017 and 2018. The data collection method in this study is the documentation study. Analysis of the data used is descriptive statistics. This study found that the disclosure of Islamic banks related to murabahah, mudharabah and musyarakah is still relatively low. There was no difference in compliance levels between the two countries during the periods of 2107 and 2018. Among the three Islamic bank products, murabaha has the highest mean. In addition, Islamic banks in Indonesia as a whole have a higher level of disclosure than Islamic banks in Malaysia.
\end{abstract}

Keywords: disclosure; murabahah; mudharabah; musyarakah; bank syariah; Accounting and Auditing for Islamic Financial Institution (AAOIFI).

How to cite (APA $6^{\text {th }}$ style)

Azlan, F.Y., \& Serly, V. (2019). Analisis Pengungkapan Standar Akuntansi Syariah AAOIFI Pada Bank Syariah di Indonesia dan Malaysia Periode Tahun 2017-2018. Jurnal Eksplorasi Akuntansi, 1(3), Seri F, 1604-1616.

\section{PENDAHULUAN}

Populasi umat muslim di dunia yaitu sebesar 1,5 miliar dari total 7,5 miliar jiwa mendorong keinginan umat muslim untuk mendirikan bank yang sesuai dengan ajaran Islam (Religion facts, 2018). Pertama kali lahirnya ide untuk membentuk bank syariah yaitu pada tahun 1940-an yang dilatarbelakangi oleh keinginan umat Islam untuk menjadikan bank syariah sebagai alternatif bank konvensional yang operasionalnya mengandung unsur ketidakpastian (gharar), riba dan perjudian (gambling).

Untuk mengatasi masalah tersebut,maka pada tahun 1963 lahirlah Mit al-Ghamr sebagai bank syariah pertama di Mesir, Islamic Development Bank (IDB) tahun 1975 di Jeddah, Faisal Islamic Bank tahun 1977 di Sudan dan Finance House pada tahun 1977 di Kuwait. Sementara di 
Asia Tenggara, perbankan syariah yang pertama lahir yaitu Bank IslamMalaysia Berhad(BIMB) pada tahun 1983 di Malaysia.

Perkembangan bank syariah di Asia Tenggara menunjukkan variasinya masing-masing. Islamic Financial Services Board (IFSB) pada tahun 2018 telah mengeluarkan data mengenai pangsa pasar bank islam beberapa negara di ASEAN. Malaysia memiliki pangsa pasar 24,9\% dari aset perbankan Malaysia. Indonesia memiliki pangsa pasar 5,4\% dari total aset perbankan nasional. Brunei Darussalam mengalami kenaikan pangsa pasar bank syariahnya menjadi 61,8\% dari total aset perbankan Brunei Darussalam. Singapura dan Thailand sebagai negara minoritas muslim memiliki pangsa pasar dibawah $1 \%$ dari total asset perbankan di negara tersebut.

Dalam rangka meningkatkan transparansi kondisi keuangan, serta penyusunan laporan keuangan yang relevan, komprehensif, andal dan dapat diperbandingkan, maka terdapat Standar Akuntansi Syariah (SAS) yang ditujukan untuk entitas yang melakukan transaksi syariah baik entitas lembaga syariah maupun lembaga non syariah di Indonesia. Pengembangan SAS dilakukan dengan mengikuti model SAK umum namun berbasis syariah dengan mengacu kepada fatwa MUI. PSAK Syariah ini sebagian besar diambil dari standar yang dikeluarkan oleh Accounting and Auditing for Islamic Financial Institution (AAOIFI). Standar AAOIFI telah digunakan sebagai dasar pengembangan standar akuntansi nasional di yurisdiksi seperti Indonesia, Malaysia dan Pakistan (AAOIFI, 2018). AAOIFI adalah organisasi nirlaba Internasional yang bertanggung jawab untuk pengembangan dan penerbitan standar akuntansi, audit, pemerintahan, etika dan tata kelola untuk keuangan Islam Internasional. AAOIFI merupakanorganisasi akuntansi syariah internasional yang berfungsi untuk penyeragaman perlakuan akuntansi lembaga keuangan syariah global.

Pemerintah Indonesia memiliki keinginan yang besar untuk menjadikan Indonesia sebagai pusat perbankan syariah di ASEAN bahkan di dunia. Sebagai negara dengan jumlah penduduk muslim terbesar di dunia sudah saatnya Indonesia mempunyai bank syariah terbesar.Oleh karena itu Pemerintah Indonesia harus menarik kepercayaan masyarakat Indonesia agar menggunakan jasa Bank Syariah, salah satunya dengan mengungkapkan prinsip-prinsip syariah pada Laporan Tahunan bank syariah sesuai dengan standar AAOIFI.Meskipun keberadaan AAOIFI sudah cukup lama, tetapi permasalahan yang dihadapi masih banyak terjadi, masih banyak lembaga perbankan yang belum atau secara penuh menjalankan pengungkapan wajib perbankan syariah, seperti pengungkapan mudharabah, murabahah dan musyarakah.

Penelitian penerapan standar AAOIFI di bank syariah sudah dilakukan di beberapa negara di dunia. Ullah (2013) meneliti kepatuhan pedoman AAOIFI tentang penyajian dan pengungkapan dalam laporan keuangan bank Islam yang terdaftar di Bangladesh. Studi ini meneliti tujuh bank Islam yang terdaftar di Bursa Saham Bangladesh dan termasuk 203 item kepatuhan. Ullah (2013) menyimpulkan bahwa tingkat kepatuhan relatif rendah karena hanya 91 dari 203 item yang diungkapkan. Oleh karena itu, ia menyarankan agar bank Islam di Bangladesh meningkatkan tingkat pengungkapan sesuai standar pada laporan keuangannya.

Nadzri (2009) menguji efektivitas dari AAOIFI dalam menangani akuntansi dan pengungkapan zakat dan riba di IFI. Dengan menggunakan analisis isi dan termasuk 25 IFI yang merupakan anggota dari AAOIFI, peneliti menyimpulkan bahwa tingkat pengungkapan lebih rendah dari persyaratan AAOIFI. Penelitian lainnya juga dilakukan oleh Husainey (2016) yang meneliti tingkat kepatuhan terhadap standar AAOIFI di negara MENA (Bahrain, Yaman, Qatar, Suriah, Palestina, Sudan, Oman, dan Jordan). Berdasarkan hasil penelitian tersebut, tingkat kepatuhan rata-rata akuntabilitas keuangan berdasarkan standar AAOIFI yaitu sebesar $73 \%$. 
Penelitian ini mereplikasi penelitian yang dilakukan oleh Al-Sulaitiet al (2017) yang menguji kepatuhan pengungkapan dengan standar akuntansi AAOIFI terkait dengan produk pembiayaan syariah pada bank-bank Islam di Bahrain dan Qatarselama periode 2012-2015. Penelitian tersebut menemukan bahwa kepatuhan pengungkapan AAOIFI murabahah, mudharabah dan musyarakah oleh bank-bank Islam di Bahrain dan Qatar relatif tinggi pada periode 2012-2015. Adapun perbedaannya dengan penelitian ini adalah dari segi objek yang diteliti dan periode penelitian. Dimana, penelitian ini meneliti Bank Syariahdi Indonesia dan Malaysia untuk periode 2017 dan 2018. Dipilihnya Malaysia sebagai perbandingan karena Malaysia adalah negara di ASEAN yang paling cepat dalam mengembangkan industri perbankan syariah.

Dalam penelitian ini, peneliti fokus pada pengungkapan tiga produk pembiayaan syariahyaitu murabahah, mudharabah dan musyarakah. Dilakukannya penelitian terhadap tiga produk pembiayaan tersebut dikarenakan ketiga produk pembiayaan tersebutlah yang paling banyak diterapkan oleh bank syariah (Vinnicome, 2012).

Berdasarkan penjelasan diatas, penelitian ini bertujuan untuk; pertama, menganalisis kepatuhan pengungkapan pelaporan keuangan berdasarkan standar yang disusun oleh AAOIFI (Accounting and Auditing Organization for Islamic Financial Institutions) pada Bank Syariah di Indonesia dan Malaysia periode 2017 dan 2018. Kedua, tulisan ini berusaha untuk memformulasikan komponen-komponen yang seharusnya dilaporkan oleh perbankan-perbankan Syariah di Indonesia dan Malaysia untuk meningkatkan transparansi dan kredibililitas di mata publik. Maka, peneliti menyimpulkan dan tertarik untuk melakukan penelitian terhadap "Analisis Pengungkapan Standar Akuntansi Syariah AAOIFI Pada Bank Syariah di Indonesia dan Malaysia Periode 2016-2018”.

\section{REVIU LITERATUR}

\section{Teori Keagenan (Agency Theory)}

Menurut Anthony dan Govindorajan (2005), salah satu elemen kunci dari teori agensi adalah principal dan agent memiliki preferensi atau tujuan yang berbeda.Jensen dan Meckling (1976) menyatakan bahwa jika kedua kelompok (agent dan principal) tersebut adalah orang-orang yang berupaya memaksimalkan utilitasnya, maka terdapat alasan yang kuat untuk agent tidak selalu bertindak yang terbaik untuk kepentingan principal.

Manajer sebagai pihak yang mengelola kegiatan perusahaan memiliki lebih banyak informasi internal dibandingkan pemilik (pemegang saham). Manajer berkewajiban untuk memberikan informasi mengenai kondisi perusahaan kepada pemilik. Informasi yang diberikan dapat dilakukan melalui pengungkapan informasi akuntansi seperti laporan keuangan. Laporan keuangan tersebut penting bagi para pengguna informasi eksternal, karena pengguna eksternal berada dalam kondisi yang paling besar ketidakpastiannya (Ali, 2002).

\section{Teori Keagenan (Agency Theory) Dalam Islam}

Etika kerja hukum Islam menjelaskan bahwa setiap individu adalah pemimpin dan bertanggung jawab terhadap kepemimpinannya, setiap orang memiliki wewenang dalam pekerjaannya dan bertanggung jawab terhadap wewenang itu dihadapan pemimpin dan Tuhan sebagaimana dijelaskan Nabi Muhammad SAW (Harahap, 1999). Secara normatif, masyarakat muslim mempraktikkan akuntansi berdasarkan pada perintah Allah SWT yang tercantum dalam surat AlBaqarah ayat 282. 
Perintah ini sesungguhnya bersifat universal dalam arti bahwa praktik pencatatan harus dilakukan dengan benar atas transaksi yang dilakukan oleh seseorang dengan orang lainnya. Substansi dari perintah ini adalah; (1) praktik pencatatan yang harus dilakukan dengan (2) benar (adil dan jujur). Substansi dalam konteks ini, sekali lagi, berlaku umum sepanjang masa, tidak dibatasi oleh ruang dan waktu. Teori Akuntansi Syariah memberikan guidance tentang bagaimana seharusnya Akuntansi Syariah itu dipraktikkan. Dengan bingkai faith (keimanan), teori (knowledge) dan praktik Akuntansi Syariah (action)akan mampu menstimulasi terciptanya realitas ekonomi dan bisnis yang bertauhid. Realitas ini adalah realitas yang di dalamnya sarat dengan jaringan kerja kuasa ilahi yang akan menggiring manusia untuk melakukan tindakan ekonomi dan bisnis yang sesuai dengan Sunnatullah (Triyuwono,2012).

\section{Pengungkapan}

Kata disclosure memiliki arti tidak menutupi atau tidak menyembunyikan (Ghozali dan Chariri, 2007). Bila dikaitkan dengan pengungkapan informasi, disclosure mengandung pengertian bahwa pengungkapan informasi tersebut harus memberikan penjelasan yang cukup dan bisa mewakili keadaan yang sebenarnya dalam perusahaan. Dengan demikian, informasi harus lengkap, jelas, akurat dan dapat dipercaya sesuai kondisi yang sedang dialami perusahaan, baik informasi keuangan maupun non-keuangan, sehingga tidak ada pihak yang akan dirugikan.

\section{Pengungkapan Standar Akuntansi Syariah (SAS)}

Hal mendasar dalam penyajian laporan keuangan akuntansi syariah adalah kewajiban untuk mengungkapkan aspek-aspek syariah, yang dimaksudkan agar laporan keuangan benar-benar dapat mematuhi ketentuan syariah dan tidak menyimpang dari prinsip-prinsip akuntansi syariah. Standar Akuntansi Syariah (SAS) adalah Pernyataan Standar Akuntansi Keuangan (PSAK) Syariah yang ditujukan untuk entitas yang melakukan transaksi syariah baik entitas lembaga syariah maupun lembaga non syariah (IAI, 2019).

\section{Akuntansi Syariah}

Napier (2017) menyatakan bahwa Akuntansi syariah adalah bidang akuntansi yang menekankan pada 2 (dua) hal yaitu akuntabilitas dan pelaporan. Akuntabilitas tercermin dari tauhid yaitu dengan menjalankan segala aktivitas ekonomi sesuai dengan ketentuan Islam. Sedang pelaporan ialah bentuk pertanggungjawaban kepada Allah dan manusia. Sedangkan Karim (2010) menyatakan Akuntansi Syariah sering juga disebut Akuntansi Islam yaitu suatu bidang baru dalam studi akuntansi, pada prinsipnya akuntansi ini dikembangkan dengan landasan nilai-nilai, etika dan syariah islam.

\section{Bank Syariah}

Menurut Undang-Undang Nomor 21 Tahun 2008 tentang perbankan syariah, yang dimaksud bank syariah adalah segala sesuatu yang menyangkut tentang bank syariah dan unit usaha syariah, mencakup kelembagaan, kegiatan usaha, serta tata cara dan proses dalam melaksanakan kegiatan usahanya. Pada dasarnya bank syariah sama dengan bank umum, yaitu perusahaan yang bergerak dalam bidang keuangan, artinya aktifitas perbankan selalu berkaitan dalam bidang keuangan. Sehingga berbicara mengenai bank tidak terlepas dari masalah keuangan.

Hanya saja bank syariah dalam menjalankan aktivitasnya, baik penghimpunan dana maupun dalam rangka penyaluran dananya memberikan dan mengenakan imbalan atas dasar prinsip syariah yaitu jual beli dan bagi hasil.Prinsip syariah yang diterapkan oleh bank syariah 
adalah pembiayaan berdasarkan prinsip bagi hasil (mudharabah), pembiayaan berdasarkan prinsip penyertaan modal (musyarakah) dan prinsip jual beli barang dengan memperoleh keuntungan (murabahah).

\section{Accounting and Auditing Organizations for Islamic Financial Institutions (AAOIFI)}

Accounting And Auditing Organization For Islamic FinancialInstitutions (AAOIFI) adalah organisasi nirlaba Internasioanl yang bertanggung jawab untuk pengembangan dan penerbitan standar akuntansi, audit, pemerintahan, etika dan tata kelola untuk keuangan Islam Internasional. AAOIFI dibentuk di Bahrain pada 27 Maret 1991. AAOIFI melaksanakan tujuan-tujuan ini sesuai dengan ajaran syariah Islam yang mewakili sistem komprehensif untuk semua aspek kehidupan, sesuai dengan lingkungan dimana lembaga keuangan Islam telah berkembang. Kegiatan ini dimaksudkan untuk meningkatkan kepercayaan pengguna laporan keuangan lembaga keuangan Islam dalam informasi yang dihasilkan tentang lembaga-lembaga ini, dan untuk mendorong para pengguna untuk berinvestasi atau menyimpan dana mereka di lembaga keuangan Islam dan menggunakan layanan mereka (AAOIFI, 2018).

\section{METODE PENELITIAN}

\section{Jenis Penelitian}

Penelitian ini merupakan penelitian kuantitatif dimana jenis penelitian kuantitatif menjelaskan tentang fakta-fakta dari objek yang diteliti dengan menganalisis data angka menggunakan metode statistik melalui pengujian hipotesis.Data yang digunakan adalah data sekunder/sumber sekunder. Penelitian ini menggunakan content analysis dalam mengungkapkan standar akuntansi syariah AAOIFI pada bank syariah di Indonesia dan Malaysia dengan unit analisis laporan tahunan bank syariah.Content analysis yaitu metode penelitian observasi yang digunakan untuk mengevaluasi secara secara sistematis isi dari suatu informasi.

\section{Sumber Data dan Teknik Pengumpulan Data}

Penelitian ini menggunakan sumber data sekunder. Pengumpulan data dalam penelitian ini menggunakan teknik dokumentasi.Data dalam penelitian ini berupa data Laporan Keuangan Bank Syariah di Indonesia dan Malaysia untuk periode 2017-2018.

\section{Populasi dan Sampel}

Adapaun populasi dalam penelitian ini yaitu 13 bank syariah yang ada di Indonesia dan 16 bank syariah Malaysia. Dalam menentukan sampel, peneliti menggunakan teknik purposive sampling. Menurut Sugiyono (2010), teknik purposive sampling adalah teknik untuk menentukan sampel penelitian dengan beberapa pertimbangan tertentu yang bertujuan agar data yang diperoleh nantinya bisa lebih representatif. Sample dalam penelitian ini adalah 12 bank umum syariah di Indonesia dan 15 bank umum syariah di Malaysia, yaitu sebagai berikut:

\begin{tabular}{|l|l|l|l|}
\hline No & Daftar Bank Syariah di Indonesia & No & \multicolumn{1}{|c|}{ Daftar Bank Syariah di Malaysia } \\
\hline 1 & Bank Muamalat Indonesia & 1 & Affin Islamic Bank Berhad \\
\hline 2 & $\begin{array}{l}\text { Bank Tabungan Pensiun Nasional } \\
\text { Syariah }\end{array}$ & 2 & $\begin{array}{l}\text { Al Rajhi Banking \& Investment } \\
\text { Corporation (Malaysia) Berhad }\end{array}$ \\
\hline 3 & Bank Rakyat Indonesia Syariah & 3 & Alliance Islamic Berhad \\
\hline 4 & Bank Syariah Mandiri & 4 & AmBank Islamic Berha \\
\hline 5 & Bank Central Asia Syariah & 5 & Asian Finance Bank Berhad \\
\hline
\end{tabular}




\begin{tabular}{|l|l|l|l|}
6 & Bank Mega Syariah & 6 & Bank Islam Malaysia Berhad \\
\hline 7 & Panin Bank Syariah & 7 & Bank Muamalat Malaysia Berhad \\
\hline 8 & Bank Negara Indonesia Syariah & 8 & CIMB Islamic Bank Berhad \\
\hline 9 & Bank Syariah Bukopin & 9 & HSBC Amanah Malaysia Berhad \\
\hline 10 & Bank Maybank Syariah Indonesia & 10 & Hong Leong Islamic Bank Berhad \\
\hline 11 & Bank Jabar Banten Syariah & 11 & Maybank Islamic Berhad \\
\hline 12 & Bank Victoria Syariah & 12 & OCBC Al-Amin Bank Berhad \\
\hline & & 13 & Public Islamic Bank Berhad \\
\hline & & 14 & RHB Islamic Bank Berhad \\
\hline & & 15 & Standard Chartered Saadiq Berhad \\
\hline
\end{tabular}

\section{Teknik Analisis Data}

Tujuan penelitian ini adalah untuk mengidentifikasi dan mendeskripsikan bagaimana pengungkapan standar akuntansi syariah AAOIFI dalam laporan tahunan bank syariah di Indonesia dan Malaysia. Untuk mencapai tujuan ini, metode analisis yang digunakan adalah teknik content analysis (analisis isi). Content analysis merupakan teknik penelitian yang digunakan untuk menentukan keberadaan kata atau konsep tertentu dalam sebuah teks atau kumpulan teks (Palmquist, 2015). Metode ini dapat diterapkan untuk mengukur pengungkapan standar AAOIFI Bank Syariah dengan menempatkan teks naratif atau jenis komunikasi untuk memudahkan analisis dalam rangka untuk memperoleh kesimpulan.

Dalam penelitian ini, jumalah item yang digunakan untuk mengukur pengungkapan standar AAOIFI pada bank Syariah di Indonesia dan Malaysia yaitu dapat dilihat pada tabel berikut:

\begin{tabular}{|c|l|}
\hline No & \multicolumn{1}{|c|}{ Item } \\
\hline & \multicolumn{1}{|c|}{ Appendix 1: Murabaha and Murabaha to the Purchase Orderer financing } \\
\hline 1 & Use of historical in measuring asset value at acquisition \\
\hline 2 & Valuation after acquisition: case 1 \\
\hline 3 & Valuation after acquisition: case 2 \\
\hline 4 & Treatment of discount after acquisition \\
\hline 5 & Murabaha receivables recorded at cash equivalent \\
\hline 6 & Murabaha receivables shown in the balance sheet \\
\hline 7 & Profit recognition: short-term Murabaha \\
\hline 8 & Profit recognition: long-term Murabaha \\
\hline 9 & Deferred profits \\
\hline 10 & Early settlement, deduction of part profit possibility 1 \\
\hline 11 & Early settlement, deduction of part profit possibility 2 \\
\hline 12 & Failure to fulfil promise \\
\hline 13 & Failure to fulfil promise when the promise is binding \\
\hline 14 & Treatment when the promise is non-binding \\
\hline 15 & Disclosure as to whether the promise is binding \\
\hline 16 & Presentation \\
\hline & \\
\hline
\end{tabular}




\begin{tabular}{|c|c|}
\hline & Appendix 2: Mudaraba financing \\
\hline 17 & Presentation in the financial statements \\
\hline 18 & Non-monetary assets should be reported as such \\
\hline 19 & Measurement of capital paid in cash \\
\hline 20 & Measurement of capital paid in kind (fair value) \\
\hline 21 & Expenses generally not to be recognised as part of capital \\
\hline 22 & Capital should be stated net of repayments \\
\hline 23 & Treatment of partial loss of capital \\
\hline 24 & Treatment of full loss of capital without negligence \\
\hline 25 & Treatment of non-received capital on termination of contract \\
\hline 26 & Recognition: short-term contracts profits or losses \\
\hline 27 & Recognition: long-term profits - as distributed \\
\hline 28 & Recognition: long-term losses - as deducted \\
\hline 29 & Recognition: long-term losses - at liquidation \\
\hline 30 & Recognition: long-term losses due to misconduct \\
\hline \multirow[t]{2}{*}{31} & Disclosure requirements \\
\hline & Appendix 3: Musharaka financing \\
\hline 32 & Recognition of Islamic Bank's share in the Musharaka Capital \\
\hline 33 & Measurement of the bank's capital share when paid in cash \\
\hline 34 & Measurement of the bank's capital share when paid in kind \\
\hline 35 & Expenses generally not to be recognised as part of capital \\
\hline 36 & Historical to measure the banks share in constant capital \\
\hline 37 & Historical cost to measure the banks share in diminishing capital \\
\hline 38 & Treatment where liquidation occurs before complete transfer \\
\hline 39 & Treatment where liquidation occurs and the banks share is unpaid \\
\hline 40 & Recognition :short-term contracts profits or losses at liquidation \\
\hline 41 & Recognition: long-term diminishing contracts profits and losses \\
\hline 42 & Recognition: long-term constant contracts profits and losses \\
\hline 43 & Recognition of losses due to partner's negligence or misconduct \\
\hline 44 & Provision should be made for doubtful receivables \\
\hline 45 & Musharaka Finance contracts should be recorded in the balance sheet \\
\hline
\end{tabular}

\section{Analisis statistik deskriptif}

Statistik yang digunakan untuk menganalisis data dengan cara mendeskripsikan atau menggambarkan data yang telah terkumpul sebagaimana adanya tanpa bermaksud membuat kesimpulan yang berlaku untuk umum atau generalisasi. Dalam statistik deskriptif antara lain adalah penyajian data melalui tabel, grafik, diagram lingkaran, pictogram, perhitungan modus, median, mean (pengukuran tendesi sentral), perhitungan desil, persentil, perhitungan penyebaran data melalui perhitungan rata-rata dan standar deviasi, perhitungan persentase. 


\section{HASIL PENELITIAN}

\section{Hasil Interprestasi Pengungkapan Standar AAOIFI di Indonesia}

Berdasarkan data pada tabel 4.1 menunjukkan bahwa prinsip syariah yang paling banyak diungkapkan oleh perbankan di Indonesia adalah Murabahah dengan rata-rata perusahaan mengungkapkan 42,19\% pada laporan tahunan yang diterbitkannya pada tahun 2017 dan 2018. Selanjutnya pada prinsip akuntansi Mudharabah, perbankan syariah hanya mengungkapkan 31,67\% pada laporan tahunan yang diterbitkannya pada tahun 2017 dan 2018. Kemudian pada musyarakah, perbankan syariah hanya mengungkapkan 27,38\% pada tahun 2017 dan 2018. Prinsip musyarakah adalah yang paling sedikit diungkapkan oleh bank syariah dibandingkan dua prinsip syariah lainnya.

Tabel 4.1

Jumlah Pengungkapan Standar AAOIFI

\begin{tabular}{|c|c|c|c|c|c|}
\hline Keterangan & Mean & Median & SD & Min & Max \\
\hline Murabahah & & & & & \\
\hline 2017 & 42.19 & 43.75 & 2.83 & 37.50 & 43.75 \\
\hline 2018 & 42.19 & 43.75 & 2.83 & 37.50 & 43.75 \\
\hline Mudharabah & & & & & \\
\hline 2017 & 31.67 & 40.00 & 15.34 & 0.00 & 40.00 \\
\hline 2018 & 31.67 & 40.00 & 15.34 & 0.00 & 40.00 \\
\hline Musyarakah & & & & & \\
\hline 2017 & 27.38 & 28.57 & 9.05 & 0.00 & 35.71 \\
\hline 2018 & 27.38 & 28.57 & 9.05 & 0.00 & 35.71 \\
\hline
\end{tabular}

\section{Perbankan dan Pengungkapan yang dilakukannya}

Berdasarkan data dapat dilihat perbankan Indonesia paling banyak telah mengungkapkan 18 item dari total 45 item yang dikeluarkan oleh AAOIFI, jika dipersentasekan yaitu sebanyak $40 \%$. Dimana bank yang paling banyak melakukan pengungkapan yaitu Bank Panin Syariah. Sementara bank yang paling sedikit melakukan pengungkapan adalah Bank BTPN Syariah yaitu sebanyak 7 item atau $16 \%$.

Tabel 4.8

Jumlah Item Diungkapkan Perbankan (2017 dan 2018)

\begin{tabular}{|c|c|c|c|c|c|}
\hline BANK & Murabahah & Mudharabah & Musyarakah & Jumlah & \% \\
\hline Bank BCA Syariah & 7 & 6 & 4 & 17 & $38 \%$ \\
\hline Bank BJB Syariah & 7 & 6 & 4 & 17 & $38 \%$ \\
\hline Bank BNI Syariah & 7 & 6 & 4 & 17 & $38 \%$ \\
\hline Bank BRI Syariah & 6 & 4 & 4 & 14 & $31 \%$ \\
\hline Bank BTPN Syariah & 7 & 0 & 0 & 7 & $16 \%$ \\
\hline $\begin{array}{c}\text { Bank Maybank Syariah } \\
\text { Indonesia }\end{array}$ & 7 & 6 & 4 & 17 & $38 \%$ \\
\hline Bank Mega Syariah & 7 & 0 & 5 & 12 & $27 \%$ \\
\hline $\begin{array}{c}\text { Bank Muamalat } \\
\text { Indonesia }\end{array}$ & 6 & 5 & 4 & 15 & $33 \%$ \\
\hline
\end{tabular}




\begin{tabular}{|c|c|c|c|c|c|} 
Bank Panin Syariah & 7 & 6 & 5 & 18 & $40 \%$ \\
\hline Bank Bukopin Syariah & 7 & 6 & 4 & 17 & $38 \%$ \\
\hline Bank Syariah Mandiri & 7 & 6 & 4 & 17 & $38 \%$ \\
\hline Bank Victoria Syariah & 6 & 6 & 4 & 16 & $36 \%$ \\
\hline
\end{tabular}

\section{Hasil Interprestasi Pengungkapan Standar AAOIFI di Malaysia}

Berdasarkan data pada tabel 4.9 menunjukkan bahwa prinsip syariah yang paling banyak diungkapkan oleh perbankan di Malaysia adalah Murabahah yaitu dengan persentase 27,92\% pada laporan tahunan yang diterbitkannya pada tahun 2017 dan 2018. Selanjutnya pada prinsip akuntansi Mudharabah, perbankan syariah telah mengungkapkan 0,89\% pada laporan tahunan yang diterbitkannya pada tahun 2017 dan 2018. Prinsip Mudharabah adalah yang paling sedikit diungkapkan oleh perusahaan dibandingkan dua prinsip syariah lainnya. Kemudian pada prinsip akuntansi musyarakah, perbankan syariah telah mengungkapkan 3,81\% pada laporan tahunan yang diterbitkannya pada tahun 2017 dan 2018.

Tabel 4.9

Rata-Rata Jumlah Pengungkapan Standar AAOIFI

\begin{tabular}{|c|c|c|c|c|c|}
\hline Keterangan & Mean & Median & SD & Min & Max \\
\hline Murabahah & & & & & \\
\hline 2017 & 27.92 & 31.25 & 11.54 & 0.00 & 37.50 \\
\hline 2018 & 27.92 & 31.25 & 11.54 & 0.00 & 37.50 \\
\hline Mudharabah & & & & & \\
\hline 2017 & 0.89 & 0.00 & 3.44 & 0.00 & 13.33 \\
\hline 2018 & 0.89 & 0.00 & 3.44 & 0.00 & 13.33 \\
\hline Musyarakah & & & & & \\
\hline 2017 & 3.81 & 0.00 & 10.05 & 0.00 & 28.57 \\
\hline 2018 & 3.81 & 0.00 & 10.05 & 0.00 & 28.57 \\
\hline
\end{tabular}

\section{Perbankan dan Pengungkapan yang dilakukannya}

Berdasarkan data dapat dilihat perbankan Malaysia paling banyak telah mengungkapkan 10 item dari total 45 item yang dikeluarkan oleh AAOIFI, jika dipersentasekan yaitu sebanyak $22 \%$. Dimana bank yang paling banyak melakukan pengungkapan yaitu RHB Islamic Bank Berhad. Sementara bank yang paling sedikit melakukan pengungkapan adalah Alliance Islamic Berhad dan Asian Finance Bank Berhad yaitu sebanyak 0 item atau 0\%.

Tabel 4.16

Jumlah Item Diungkapkan Perbankan (2017 dan 2018)

\begin{tabular}{|c|c|c|c|c|c|}
\hline BANK & Murabahah & Mudharabah & Musyarakah & Jumlah & \% \\
\hline Affin Islamic Bank Berhad & 5 & 0 & 0 & 5 & $11 \%$ \\
\hline $\begin{array}{c}\text { Al Rajhi Banking \& Investment } \\
\text { Corporation (Malaysia) Berhad }\end{array}$ & 6 & 0 & 0 & 6 & $13 \%$ \\
\hline Alliance Islamic Berhad & 0 & 0 & 0 & 0 & $0 \%$ \\
\hline
\end{tabular}




\begin{tabular}{|c|c|c|c|c|c|} 
AmBank Islamic Berhad & 5 & 0 & 0 & 5 & $11 \%$ \\
\hline Asian Finance Bank Berhad & 0 & 0 & 0 & 0 & $0 \%$ \\
\hline Bank Islam Malaysia Berhad & 5 & 0 & 0 & 5 & $11 \%$ \\
\hline Bank Muamalat Malaysia Berhad & 5 & 0 & 0 & 5 & $11 \%$ \\
\hline CIMB Islamic Bank Berhad & 5 & 2 & 0 & 7 & $16 \%$ \\
\hline HSBC Amanah Malaysia Berhad & 5 & 0 & 0 & 5 & $11 \%$ \\
\hline Hong Leong Islamic Bank Berhad & 5 & 0 & 0 & 5 & $11 \%$ \\
\hline Maybank Islamic Berhad & 5 & 0 & 4 & 9 & $20 \%$ \\
\hline OCBC Al-Amin Bank Berhad & 5 & 0 & 0 & 5 & $11 \%$ \\
\hline Public Islamic Bank Berhad & 5 & 0 & 0 & 5 & $11 \%$ \\
\hline RHB Islamic Bank Berhad & 6 & 0 & 4 & 10 & $22 \%$ \\
\hline OCBC Al-Amin Bank Berhad & 5 & 0 & 0 & 5 & $11 \%$ \\
\hline
\end{tabular}

\section{PEMBAHASAN}

Hasil interpretasi data menemukan bahwa bank syariah di Indonesia dan Malayasia memiliki tingkat kepatuhan terhadap standar akuntansi keuangan AAOIFI terkait dengan murabahah, mudharabah, dan musyarakah yang tergolong rendah. Standar murabahah memiliki rata-rata kepatuhan tertinggi. Selain itu, hasil penelitian menunjukkan bahwa bank-bank syariah di Indonesia cenderung memiliki kepatuhan lebih tinggi baik pada standar pengungkapan murabahah, mudharabah, dan musyarakah dibandingkan dengan bank-bank syariah yang ada di Malaysia.

Dibandingkan dengan penelitian sebelumnya oleh Sulaiti et al (2018) yang meneliti pada bank islam yang terdapat di Bahrain dan Qatar menunjukkan bahwa bank-bank islam di kedua negara tersebut jauh lebih patuh dalam melaksanakan standar akuntansi keuangan AAOIFI, dimana tingkat pengungkapan standar AAOIFI di Qatar secara keseluruhan mencapai lebih dari 75\%. Sementara tingkat pengungkapan standar AAOIFI di Qatar secara keseluruhan juga mencapai lebih dari 75\%. Hasil tersebut tentu jauh berbeda jika dibandingkan dengan pengungkapan standar AAOIFI di Indonesia dan Malaysia, dimana secara keseluruhan tingkat pengungkapan standar AAOIFI di Indonesia hanya lebih dari 30\%. Sedangkan Malaysia bahkan lebih rendah yaitu hanya mencapai lebih dari $10 \%$. Tingkat perbedaan kepatuhan ini diduga dapat disebabkan oleh perbedaan regulasi dan budaya pada masing-masing negara.

Pengungkapan standar AAOIFI yang dilakukan bank Syariah Indonesia dan Malaysia memiliki sedikit kesamaan dengan bank Islam di Bahrain dan Qatar, yaitu pengungkapan tertinggi terdapat pada prinsip murabahah, prinsip Murabahah merupakan akad jual beli barang pada harga asal dengan tambahan keuntungan yang disepakati. Penjual harus memberi tahu harga produk yang dibeli dan menentukan suatu tingkat keuntungan sebagai tambahannya. Jual beli ini dapat dilakukan untuk pembelian secara pesanan. Prinsip Murabahah dalam standar AAOIFI terdiri dari 16 item.

Terdapat perbedaan antara pengungkapan standar AAOIFI yang dilakukan bank Syariah Indonesia dan Malaysia dengan pengungkapan standar AAOIFI bank Islam di Bahrain dan Qatar, yaitu penelitian Sulaiti et al (2018) yang meneliti dari tahun 2012-2015 menemukan bahwa terdapat peningkatan yang signifikan dari tahun-tahun pada pengungkapan murabahah, mudharabah, dan musyarakah khususnya pada tahun 2012 ke tahun 2013. Sedangkan pada bankbank syariah di Indonesia dan Malaysia tidak ditemukan peningkatan pengungkapan standar AAOIFI selama periode pengamatan yaitu tahun 2017 dan tahun 2018 . 


\section{KESIMPULAN DAN SARAN \\ Kesimpulan}

Berdasarkan analisis data dan interprestasi mengenai pengungkapan standar akuntansi syariah AAOIFI dalam laporan tahunan bank syariah di Indonesia dan Malaysia, dapat ditarik kesimpulan sebagai berikut:

1. Tingkat pengungkapan yang dilakukan perbankan syariah Indonesia lebih besar dibanding pengungkapan yang dilakukan perbankan syariah Malaysia, dimana rata-rata pengungkapan yang dilakukan perbankan syariah Indonesia yaitu pada murabahah sebesar $41,25 \%$, pada mudharabah sebesar $28,00 \%$, dan pada musyaraka sebesar $25,71 \%$. Sementara rata-rata pengungkapan yang dilakukan perbankan syariah Malaysia yaitu pada murabahah sebesar $27,92 \%$, pada mudharaba sebesar $0,89 \%$, dan pada musyarakah sebesar $3,81 \%$.

2. Pengungkapan tertinggi terdapat pada prinsip syariah murabahah, dimana pada perbankan syariah Indonesia diperoleh nilai maksimum 43,75\% dan pada perbankan syariah Malaysia diperoleh nilai maksimum sebesar $37,50 \%$.

3. Tidak terjadi peningkatan apapun pada pengungkapan murabahah, mudharabah dan musyarakah selama tahun 2017 hingga tahun 2018, baik pada perbankan syariah Indonesia maupun perbankan syariah Malaysia

4. Berdasarkan item-item yang diamati, perbankan cenderung lebih megungkapkan prinsip syariah musyarakah yang bersifat umum dan berkaitan langsung dan aktivitas yang dapat mempengaruhi keuangan perbankan dan cenderung tidak mengungkapkan hal-hal terkait kesepakatan yang dibangun dengan pihak lain maupun hal-hal yang dapat merusak nama baik bank dimata publik

\section{Saran}

1. Penelitian ini hanya menganalis pengungkapan murabahah, mudharabah, dan musyarakah, penelitian selanjutnya dapat menambah produk bank syariah yang akan diteliti, sekaligus menambah periode penelitian.

2. Peneliti selanjutnyadapatmeneliti dapat menyelidiki analisis tambahan seperti kausalitas hubungan.

\section{DAFTAR PUSTAKA}

Abdullah, R. Mohamed. 2011. Development of Islamic Banking in Malaysia. KLRC Newsletter Accounting and Auditing Organization for Islamic Financial Institution. 2018. http://aaoifi.com/?lang=en

Ali, Irfan. 2002. Pelaporan Keuangan dan Asimetri Informasi dalam Hubungan Agensi. Lintasan Ekonomi Vol. XIX. No.2. Juli 2002

Anthony, R.N., and V. Govindarajan. 2005. Management Control Systems. Homewood, Illinois: McGraw-Hill

Bank Indonesia. 2008. Undang-Undang Republika Indonesia Nomor 21 Tahun 2008 Tentang Perbankan Syariah. www.bi.go.id

Belkaoui, Ahmad Riahi. 2006. Accounting Theory. Edisi Kelima. Jakarta: Salemba Empat

Brealey RA., Myers SC, Marcus AJ. 2008. Dasar-dasar Manajemen Keuangan Perusahaan. Sabran B, penerjemah. Jakarta: Erlangga. Terjemahan dari: Fundamentals of Financial of Management 
Darrough, M.N. 1993. Disclosure Policy and Competition: Courtnot vs Bertrand. The Accounting Review, Vol.68 No.3, pp. 534-561

Fraenkel, J. R. \& Wallen, N. E. 2007. How to Design and Evaluate Research in Education. Singapore: The McGraw-Hill Companies

Ghozali, I. dan Chariri, A. 2007. Teori Akuntansi. Semarang: Badan Penerbit Universitas Diponegoro

Harahap, Sofyan Syafri. 1996. Akuntansi Islam. Jakarta, Bumi Aksara

Harahap, Sofyan Syafri. 2010. .Analisa Kritis atas Laporan Keuangan. Cet 11. Jakarta: PT RajaGrafindo Persada

Ikatan Akuntansi Indonesia. 2018. SAK Syariah Efektif Per 1 Januari 2018. http://www.iaiglobal.or.id/v03/standar-akuntansi-keuangan/sas-efektif-16-sak-syariahefektif-per-1-januari-2018

Ikatan Akuntansi Indonesia. 2018. Standar Akuntansi Keuangan Syariah. http://www.iaiglobal.or.id/v03/standar-akuntansi-keuangan/syariah\#

Islamic Financial Services. 2018. IslamicFinancial Services Industry Stability Report 2018.https://www.ifsb.org/docs/IFSB\%20IFSI\%20Stability\%20Report\%202017.pdf

Jabir Al-Sulaiti, Abdulrahman Anam Ousama, Helmi Hamammi. 2017. The compliance of disclosure with AAOIFI financial accounting standards: a comparison between Bahrain and Qatar Islamic banks. Journal of Islamic Accounting and Business

James H. McMillan \& Sally Schumacher. 2010. Research in Education. USA: Pearson Education

Jensen \& Meckling. 1976. The Theory of The Firm: Manajerial Behaviour, Agency Cost, and Ownership Structure. Journal of Financial and Economicz, 3:305-360

Kamla, R. 2007. Critically Appreciating Social Accounting and Reporting in the Arab MiddleEast: A Postcolonial Perspektive.Advance in Internasional Accounting 20 (2007): 105-177

Karim, A Adiwarman. 2010. Bank Islam (Analisis Fiqih dan Keuangan). Jakarta: PT. RajaGrafindo Persada

Kayadibi, Saim. 2010. The Growth of Islamic Banking and Finance in Malaysia, Islamic Finance - Chapter III

Kusumawati, Zaidah. 2005. Menghitung Laba Perusahaan: Aplikasi Akuntansi Syariah. Cet.I.Yogyakarta:Magistra Insani Press

Lexy J. Moleong. 2010. Metodologi Penelitian Kualitatif. Bandung: PT Remaja Rosdakarya

Malaysian Accounting Standards Board. http://www.masb.org.my/pages.php?id=203

Miles, M. B dan A. M. Huberman. 1992. Qualitative Data Analysis: A Sourcebook of New Methods. SAGE. Beverly Hills

Nadzri, F. 2009. Roles and impacts of accounting and auditing organization for Islamic financial institutions (AAOIFI) in dealing with the accounting and disclosure of Zakah and interest (Riba). Doctoral dissertation, Auckland University of Technology

Sherif El-Halaby Khaled Hussainey. 2016. Determinants of compliance with AAOIFI standards by Islamic banks. International Journal of Islamic and Middle Eastern Finance and Management, Vol. 9 Iss 1 pp. -

Napier, C. 2007. Other Cultures, Other Accountings? Islamic Accounting From Past to Present. In 5th Accounting History International Conference, Banff, Canada, 9-11

Religion Fact. 2018. The Big Religion Chart.www.religionfacts.com/big-religion-chart 
Ruziana, M., dan Norilawati, I. 2008. The Development of Islamic Banking Laws in Malaysia: An Overview. Jurnal Undang-Undang, 2008, pp.191-205

Scott, William R. 2000. Financial Accounting Theory. Second edition. Canada: Prentice Hall

Sekaran, Uma. 2011. Research Methods for businessEdisi I and 2. Jakarta: Salemba Empat

Sudarsono, Heri. 2012. Bank Dan Lembaga Keuangan Syariah: Deskripsi Dan Ilustrasi. Yogyakarta: Ekosoria

Sugiyono. 2013. Metode Penelitian Pendidikan Pendekatan Kuantitatif, Kualitatif, dan R\&D. Bandung: Alfabeta

Surat Keputusan Direksi bank Indonesia Nomor 32/34/ KEP/DIR/tanggal 12 Mei 1999 Tentang Bank Umum Berdasarkan Prinsip Syariah

Suwardjono. 2008. Teori Akuntansi: Perekayasaan Pelaporan Keuangan.Yogyakarta: BPFE

Triyuwono, Iwan. 2012. Akuntansi Syariah perspektif, metodologi dan Teori. Jakarta: PT Raja Grafindo Persada

Ullah, md.Hafij. 2013. Compliance of AAOIFI guidelines in general presentation and disclosure in the financial statements of Islamic bank in Bangladesh. International journal of social science research, vol. 1 Issue 2. pp:111-123, ISSN 2289 - 3318

Yanto, Sri. 2003. Standar Akuntansi Perbankan Syariah. Disampaikan daiam Seminar Nasional Akuntansi Syariah, Jogja Hail Hotel Santika, Yogyakarta

Yunus, k. 2004. Investment in Islamic Fund soars. Business Times. Kuala Lumpur, June 23, p. 2. 